This item was submitted to Loughborough's Research Repository by the author.

Items in Figshare are protected by copyright, with all rights reserved, unless otherwise indicated.

\title{
Role of ergonomics in re-designing job design in call centres
}

PLEASE CITE THE PUBLISHED VERSION

https://doi.org/10.1080/10803548.2019.1630111

PUBLISHER

Taylor \& Francis

VERSION

AM (Accepted Manuscript)

PUBLISHER STATEMENT

This is an Accepted Manuscript of an article published by Taylor \& Francis in International Journal of Occupational Safety and Ergonomics on 26 August 2019, available online:

http://www.tandfonline.com/10.1080/10803548.2019.1630111.

\section{LICENCE}

CC BY-NC-ND 4.0

\section{REPOSITORY RECORD}

Ahmed, Silvia. 2019. "Role of Ergonomics in Re-designing Job Design in Call Centres". Loughborough University. https://hdl.handle.net/2134/38077. 
2

3

Role of ergonomics in re-designing job design in call centres

4

5

6

Author

7

Silvia Ahmed Khattak

8

9

10

Author affiliations

11

Management Sciences Department, Bahria University, Islamabad

12

Pakistan

13

14

e-mail: S.Ahmed2@lboro.ac.uk

15

16

17

18

19

20

21

22

23

24

25

26 


\section{Title: Role of ergonomics in re-designing job design in call centres}

\section{Abstract}

\section{Purpose of the article}

30 Ergonomics focus, regarding job design is to address the issue of fitting the job to the worker.

31 This means that other things such as space, matter, pedagogical parameters and organizational 32 environment need to be adjusted to the worker, to obtain optimal performance. Hence it is 33 important that jobs are designed in a way that the environment of the worker becomes 34 ergonomically better.

\section{Methods}

36 Seventeen interviews were taken from employees of call centres of three major telecom 37 companies in Islamabad. The interviews were semi-structured and NVivo 10 was used for 38 analysis.

\section{Results}

40 The results indicated the influence of the following ergonomic factors on job design.

41 i) Force, mental well-being, and supervisor and peer support acted more on complexity of task.

42 ii) Inappropriate postures, mental well-being, characteristics of work, supervisor and peer 43 support and work environment acted on skill and efforts required.

44 iii) Repetitiveness, workstation design, mental well-being, supervisor and peer support, work 45 environment and characteristics of work acted more on degree of worker control.

\section{Conclusion}

47 It was concluded that the issues related to these factors should be addressed, to improve job 48 designs at workplace.

\section{Keywords}

50 Job design, physical ergonomics, cognitive ergonomics, organizational ergonomics, call 51 centres 


\section{Introduction}

57 The term Ergonomics was first used by a Polish scholar Wojciech Jastrzebowski. It did not

58 come into notice until the book that he wrote in polish in 1857 was translated in English in 591997 and was not formally recognized in the organizational context until the early $20^{\text {th }}$ century 60 [1].

61 According to International Ergonomic Association 'Ergonomics (or human factors) is the 62 scientific discipline concerned with the understanding of interactions among humans and other 63 elements of a system, and the profession that applies theory, principles, data and methods to 64 design in order to optimize human well-being and overall system performance' [2]. Perhaps 65 when looking back at the roots of ergonomics, one might find that Greeks were concerned with how things could have been picked up in the right position due to their interaction and concerns

67 for the worker class [3].

68 If human interaction with its working environment is the point of concern, then many theories 69 can be related to workers and ergonomics. One of them is balance theory, using the cognitive 70 consistency motive to balance the psychological aspect of the worker. The reliance on the 71 psychological aspect of this theory for determining the behaviour of the worker is limiting 72 because it is unable to explain the interactive process between the worker and the environment 73 [4]. Similarly social comparison theory has its underpinnings in accuracy of self-evaluation. 74 This process happens by comparing oneself with others to determine qualities of self [5]. 75 Apparently, heterophily theory is a one which comes out of the psychological context and 76 somehow focuses on interaction with unlike minded people to promote innovativeness [6].

77 Henceforth, the most relevant theories that incorporate interaction of human beings with 78 structures, objects and systems are socio-technical systems and actor network theory. The actor 79 network theory states the role of the actor who is the main role in this theory and his interaction 80 with the environment and objects. It is a free-flowing model, where boundaries of the system 81 are less enhanced as compared to the socio-technical systems [7].

\section{Problem Statement}

83 In order to study the effects of components of ergonomics, it is important to know the effect of 84 each of these on the job design components. Redesigning jobs considering ergonomic factors 85 will lead to more insightful reconsideration of factors that enables and enhance performance of 
the organization, however, this is yet to be researched. Hence the study aims at addressing the following question:

"To what extent can ergonomics be incorporated into job designs to make the workplace of a call center employee a better one?"

\section{Literature Review}

\subsection{Physical Ergonomics}

Waters and McDonald [8] raise attention towards increasing musculoskeletal disorders in the United States because of the demand of the job exceeding the required limit. The authors here are trying to argue that as population will age more, there will be more of health issues pertaining to employees and hence it becomes important that jobs be designed in such a way that the physical ergonomic content is taken into account.

In a survey about school children, ageing 10-17 using laptops in Western Australia, Harris and Straker [9] found that $60 \%$ of the students did not feel comfortable using their laptops and $61 \%$ were dissatisfied with carrying their laptops. Resnick and Chaffin [10], found out that a work surface height of $67 \mathrm{~mm}$ for US employees is suitable, but it is not for Columbian workers, since their average heights are lower than the US citizens. Sharan [11] argues that if there are musculoskeletal disorders existing in employees, it might lead to financial burden on both the employer and the employee. Cuesta et.al [12] provides a unique solution of incorporating job rotation schedules to the job and making it ergonomically better.

\subsection{Cognitive Ergonomics}

Cognitive ergonomics, as the name indicates, has to do with mental comfort ability of the employee [13]. Some workers do not like the use of computers frequently for getting their tasks completed, others might dislike manual work; indicating that theories of human behaviour also intervene at this level [14]. Green and Hoc [15] discusses that perhaps it is more important to establish a relationship between a person who do the job and the person who designs the job. In order to attain the optimal results, it is important that both the factors are considered. An architect will need both design and the utility of a building, to make a good blueprint of the designed building.

\subsection{Organizational Ergonomics}

Mcphee [16] argues that other than the physical component of ergonomics, factors such as job content, balancing work demand and support and training are aspects which are equally important in determining the design of the job. A study by Cohen [17] revealed a consultant 
118 view on the failure of management and design of the organization in exposing employees and

119 causing injuries because of exposure to the harmful chlorine gas. Another study by Carayon,

120 Hoonaker and Haims [18] focused on project teams intervening during work settings, proposed

121 new policies which were then incorporated into an overall organizational ergonomics

122 framework.

123 Other researchers have taken factors of organizational ergonomics into consideration which 124 has to do more with eco-friendliness naming the jobs as "green jobs". Green jobs reduces not 125 only physical hazards, it also enhances cognitive meaning to the job and is effective in 126 organization sustainability as well [19].

\section{$127 \quad 2.4$ Job Design}

128 Job components of a job design could be designed ergonomically to attain optimal performance 129 from an employee. Das and Sengupta [20] discusses how industrial workplaces can be made 130 better by considering lateral clearance, normal and maximum working areas, adequate posture, 131 work height and visual clearance. They discuss that these factors can be designed in order to gain maximum output from an average worker. The design of organizational work, as Oldham

133 and Hackman [21] simplistically defines it, job design is a major component of internal 134 organizational context.

135 John [22] states that job characteristics in job design might carry a somewhat complicated dual 136 relationship in a variety of contexts. For example, autonomy in one context might produce 137 better performance but in another context might be exercised to end up in solutions that have 138 nothing to do with the real problem. It is therefore important to design the context first.

139 Hertel [23] on his discussion on open source software projects has argued that it is more 140 important if work oriented perspective in designing jobs is kept in mind as compared to person 141 oriented perspective. It is because such a design can be replicated in various situations and 142 contexts.

\section{$143 \quad 2.5$ Ergonomics and job design in call centres}

144 Sprigg and Jackson [24] indicate the role of work design as a mediating factor in determining 145 strain in call centre employees. They took pre-determined factors of work design such as i) 146 Timing control ii) Method control iii) Workload iv) Role conflict v) Role clarity vi) Task 147 variety vii) skill utilization. They state that if these factors are controlled, it will lead to more 148 lean management and particularly dialogue scripting and performance management. Call 
149 centre employees, however, dislike electronic monitoring and the mechanistic form of call 150 centre work $[25,26]$

151 Kraemer and Gouthier [27] contended that if emotional exhaustion of employees is reduced 152 and organizational pride of the employees is enhanced, it will reduce the turnover intentions of 153 call centre employees. Moss et al. [28] provides a contrary view of call centres being 154 mechanistic in their study in the USA on call centres and have put forward a stance that in an era where job security is being dismantled and jobs have been restructured, it is interesting to find that in the USA, jobs have actually been broadened in the call centres.

157 Schulze [29] in a newspaper article talks about workstation ergonomics. He emphasizes the 158 fact that objects alone cannot fulfil the ergonomic needs of a worker. A worker also needs 159 adjustments to objects and body postures, to have a better ergonomic environment at workplace.

\section{Theoretical Framework}

162 Job design includes complexity of task, skill and effort and degree of worker control and is a 163 part of work organization [30, 31]

164 The researcher has taken these job design elements as core components at the heart of the model 165 and has examined the ergonomic factors which have a greater role in affecting these elements 166 of job design.

167 The factors of the three form of ergonomics which can affect a call centre employee's work are 168 given below:

- factors in physical ergonomics such as i) repetitiveness, ii) force, iii) poor workstation design and iv) inappropriate postures,

- factors in cognitive ergonomics such as i) perceived characteristics of work and ii) mental well being

- factors of organizational ergonomics such as i) supervisor and peer support ii) work environment These factors were shortlisted by the team leads working in the call centres. of call centre employees.

Figure 1. Theoretical framework of ergonomic factors in job design 


\section{Study Design}

\section{$183 \quad 5.1$ Methodology}

184 This research is descriptive in nature and follows an interpretive phenomenon to have a 185 complete insight into the understanding of human factors. The research approach used is 186 inductive, since suggestions for job design forms are indicated. The time horizon utilized here 187 is cross sectional, with studying multiple units at one point in time. Survey methods are 188 involved in the study. Survey method involves Semi structured interviews.

\section{$189 \quad 5.2$ Participants}

190 The participants included are call centre employees from 3 major telecommunication 191 companies in Islamabad. The inclusion criterion was that the employees should have worked 192 for one year in the call centre. The age range was between 18 to 60 years. There were no 193 limitations on age within this criterion. 17 employees took participation, of whom 10 were 194 male respondents and 7 were female respondents.

\section{$195 \quad 5.3$ Sampling}

196 The sampling method is non-probability sampling. Within this umbrella sampling method, 197 purposive homogeneous sampling and then convenience sampling technique has been used. 198 NVivo 10 has been used to group major categories in the study.

\section{$199 \quad 5.4$ Methods}

200 Pilot interviews were taken from 2 employees of one of the major telecom call centre 201 employees. The method includes semi structured interviews. These interviews were aimed at 20240 minutes duration. The broader categories were already defined, as indicative in the 203 theoretical framework. More insights were drawn from the participants, using these categories.

\section{Results}

205 The results are based on 17 interviews from call centre employees. The results indicate the 206 extent of role of factors influencing the job design of these call centre employees. These apparent and prominent factors are indicated in the analysis as well. The analysis has been carried using NVivo 10. This analysis will lead to implications for other call centres for better ergonomic models in the workplace. 
210 Table 1 and Table 2 indicate the views of 17 employees regarding the ergonomic factors 211 involved in job design.

212 Table 1. Count of respondents' opinion of ergonomic factors involved in job design

213 Table 2. Continuation of count of respondents' opinion of ergonomic factors involved in job 214 design

\section{Analysis}

\section{$216 \quad 7.1$ Physical Ergonomics}

\section{1 a. Musculo-skeletal disorders from force and complexity of task.}

218 According to the count given in this paper (table 1), most answers came from the factor that 219 force did contribute to the complexity of task, leading to several musculo-skeletal disorders. It 220 can also be seen from the secondary literature that musculo-skeletal disorders have been 221 indicated in various cases and examples.

222 Yes, it does, we have to work for about 8 tol0 hours a day and it is the job with all kind of 223 physical as well as mental stress. I must be on my seat for quite long which cause neck pains,

224 back pains as well as eye and ear pain.

225 Headaches and body pains are very common and it's a part of the job. If I have to name a few, 226 the eye stress is at the first place because we have to look at the computer screen for hours and 227 because of it our eyes start burning a bit; after that ear stress and then stress caused due to 228 continuous sitting on the seat.

229 Basically this has been indicated due to working longer hours. In this case the respondents 230 thought that if one sits for longer time duration, then working on smaller tasks makes it complex 231 and requires exertion of force. So force is an indirect factor in complexity of task but a major 232 one. Apparently lesser respondents agreed that force is involved in skill development or degree 233 of worker control.

\section{$234 \quad 7.1$ b. Repetitiveness}

235 Most of the respondents agreed that employees can have more control over their work by 236 repeating a task. One of the respondent stated the above fact in the following way: 
237 Repetitiveness, though monotonous, increases the degree of worker's control over the job. It is

238 exactly like driving for the first time and then the 80th time. Obviously, there is going to be a

239 huge improvement in driving skills at the 80th time because one is repeating it. Nonetheless,

240 sometimes it gets boring.

\section{1 c. Monotony and Boredom}

242 Interestingly, another factor which emerged from the results was monotony and boredom.

243 Some respondents stated that repetitiveness leads to monotony and boredom.

244 Definitely, there is monotony. But on and off some events are planned, such as going to Pearl

245 Continental Hotel Bhurban or having a ping pong table tennis game. Some dinners are also

246 planned. If we don't have these activities, people tend to leave the job.

247 Ohyes, if we didn't have recreational activities, then our work is so monotonous, that we would 248 have died out of monotony.

249 It does not make the task more complex, however, it becomes very irritating repeating the same 250 thing again and again. Also in meeting sessions, a lot of sessions seem to be repetitive, which 251 makes it very boring.

\section{$252 \quad 7.1$ d. Inappropriate Postures}

253 Most of the respondents agreed that unhealthy/inappropriate postures affect skill development.

254 Some of them responded in the following way:

255 Sometimes, unhealthy postures resulting in problems such as neck sprains, might hinder the 256 skill development.

257 Yes, I have longer legs and if I don't get up and walk around in half hour or so, they seemed 258 to get clamped.

\section{1 e. Workstation design and degree of control}

260 Most respondents agreed that workstation design or system design has contribution in degree 261 of worker's control.

262 Yes, it will, we are too used to our setup and if there is a slight change, it will translate 263 accordingly to the control we have over our work. 
264 Yes, for example if you are sitting upright on a chair, this means that there is a tendency that 265 one will work better but if somebody is slumped in a chair, this means that they are lethargic and hardly focusing on worker's control.

$267 \quad 7.2$ Cognitive Ergonomics

2687.2 a. Mental Well-being and complexity of task

269 Most of the respondents agreed that mental satisfaction is related to skill development and 270 degree of worker control but lesser to complexity of task. A major area that emerged was that

271 of lesser compensation. Respondents indicated that less remuneration was the reason for mental

272 dis-satisfaction. Some of the quotes indicating this area are given below

273 The fact that there is no incentive and benefit for good work makes us less spirited and less 274 sanguine about the organization.

275 We work for quite longer hours and we need to be very careful while talking to the customers. 276 It is quite a stressful job and for this what we are compensated is actually meagre and peanuts.

277 If this goes on, our mental satisfaction with the job will definitely decrease and not increase.

278 Initially we thought that we were here to earn something and that we will get good salaries but 279 as the job is tough and we complete our task on time, in the end our salary disappoints $280 u$ us...because the salaries are not at par with the type of work we are producing.

\section{2 b. Mental well-being and worker's control and skills}

282 Most of the respondents agreed that meaningful work provides more control over the work and 283 enhances skills, but several respondents agreed that this was mainly because of product 284 knowledge, so product knowledge provided more control in this regard. Skill development was 285 mainly because of trainings

286 As far as worker's control is concerned, there is an important aspect. If you increase their 287 knowledge on the specific product that they are working on, it increases their control. So 288 product knowledge is one important factor that they need to have training on.

289 Creativity at work actually increases the degree of worker's control over his/her job. This is 290 because, at a time, a worker has to do various tasks because of which the knowledge of the 291 worker is enhanced.......again which means there is going to be more control over the job. 
292 Yes, as I told you, trainings and workshops can increase creativity. Whenever I attend a 293 training or workshop, I feel that I am empowered, and I feel that there is more creativity in my 294 work.

295 Because our trainings and the kind of work that we have is pre-determined so everything is pretty under control and tasks are not very difficult.

7.2 c. Characteristics of work and degree of worker control, skills, complexity of task:

298 Characteristics of work were well defined and respondents did not find any difficulties in task complexity. It also gave them control over the work and did not hinder the skills as well.

\subsection{Organizational Ergonomics}

301 Most of the respondents agreed that supervision style and peer support influences worker's control, skills and complexity of task. Some interesting findings are quoted below

303 Well not on complexity, but it does have an effect on willingness of the employee. Sometimes 304 the morale of the employee is affected.....sometimes there are discomfort zones between the 305 boss and the subordinate, but it does not go beyond a certain extent. We try to finish the matter as soon as possible; the sooner it is resolved the better it is.

307 Yes, scratching back increases responsibilities of the workers. If there is an environment of 308 mutual trust between the supervisor and the employee, then obviously, the worker feels obligated to do extra for the organization or the boss in this case.

310 It's a natural thing that if you enjoy good working relations, you are going to benefit from it 311 and if you have bad working relations, then you will suffer. Good working relations can sometimes prove an obligation but by and large, I think it has a positive effect rather than 313 negative.

\section{$314 \quad 7.3$ a. Environmental factors}

315 Most of the respondents did agree that work environment did provide worker control over the 316 job.

317 No, I don't think the environment here is very official. I can see biases and I can see nepotism, 318 but Idon't think it prevails in an extensive form. What is more important is that the environment 319 should be more relaxed..... and nobody should be under immense or undue pressure and strict 320 deadlines. 
The meeting times here are quite extensive. These should be reduced to increase productivity.

322 Succession planning is practiced rigorously here. The interests of the employees are matched 323 with the opportunities available at the organization. For example we have training positions and quality assurance positions.....so these are matched with the employees interests. Through succession planning, internal promotions are encouraged and hence attrition rate can be reduced.

327 However an interesting factor emerged from this question. In light of the then political scenario, some of the respondents pointed at the fact that situations like political instability and natural calamities affect the control over their work, which also included the effect on their skill development.

In Pakistan, there is turbulence anyways, whether it is political or geographical, such as these sit-ins at the red zone.....or the floods. These have affected our work schedules in a great way. Sometimes we are being called on odd times, which also disturb our family lives.

334 For example, seasonal and event factors reduces/increases call volume. If there is Eid coming 335 up, then the volume of the calls increases. If there are major sporting events, such as football 336 or cricket world cup, then again the attitude and the volume of calls increase. If the season or 337 the tournament ends up in positive result, the attitude of the customer becomes delightful.

\section{$338 \quad 8$ Findings}

339 The above inside views from the employees has allowed the researcher to draw out certain 340 findings. Without these views from the respondents, it would have been difficult to draw 341 inferences. Figure 2 shows the prominent ergonomic factors influencing the three job design 342 elements; complexity of task, skill and effort and degree of worker control.

343 Figure 2. Ergonomic factors influencing the three job design elements

\section{$344 \quad 8.1$ a. Complexity of task}

345 From the analysis, we can see that three ergonomic factors acted more on complexity of task. 346 One of it was force. This did not mean physical exertion; in fact, small amount of force such 347 as reaching out for something repetitively, created health issues. This in turn resulted in making 348 the task more complex.

349 Secondly, when employees do not find output from their work, whether it is intrinsic or 350 extrinsic, they feel that their task is getting complex. In the intrinsic form, we had several 351 responses of monotony and boredom. In the extrinsic form, employees were not satisfied with 352 their remuneration. Most of them responded that a salary of meagre Rs. 15000/- was not enough 353 for an 8 hour shift duty.

354 Thirdly, supervision style and lack of peer support contributed to complexity of task. The 355 researcher had some interesting responses in this regard. Employees thought that both good and bad rapport with the supervisor and peers contribute to making the task more complex. In 
case of good rapport, it becomes an obligation to do something extra for the organization and in case of bad rapport, people make your tasks difficult to achieve.

359 It is also very interesting to note that all the three factors do not influence the complexity of

360 task directly, but it has an indirect effect acting on it.

\section{$361 \quad 8.1$ b. Skill and effort required}

362 One of the major factors that were involved in skill and effort was inappropriate postures. One 363 of the respondents stated that their mouse clicking ability was reduced because of the stiffness 364 in the hands and fingers of the employees. This meant that more of skill and effort was required 365 at this stage to carry out this task.

366 Another factor which contributed to the skill effectiveness was mental well-being, or creativity 367 at work. Several respondents were of the view that non-related job trainings enhanced their 368 creativity. Because of empowerment, they thought that their skills increased.

369 Respondents agreed that if characteristics of work are well defined, skills are well developed 370 too. Generally the trainings and the skills of the call centre employees are such that they are 371 very well defined. For this reason, the respondents felt that related trainings enhance their 372 skills; but there was a lack of non-related trainings, due to which they felt insecure about their 373 advancement in the career.

374 Respondents also provided their opinion about role of supervision style and peer support in 375 enhancement of skills. They were of the view that if work relations with supervisors and peers 376 are good in general, one is more satisfied and is keener on learning and developing the skills. 377 On the other hand, if work relations are not good enough, it leads to stress, hindering the skill 378 enhancement ability of the employee.

379 Work environment was another major factor which affected the skill development of the 380 employees. Again, the respondents agreed that if work environment was conducive, which in most cases was conducive, then employees had less stress on their mind, and they could focus 382 more on their skills and job-related issues. In case if it was not conducive, then it hampered 383 their abilities to excel in their career.

\section{1 c. Degree of worker control}

385 One of the major ergonomic factors for worker's control over their job was repetitiveness. 386 Respondents agreed to the fact that repetitiveness of a task gives them more control over their 387 job. Only a few thought otherwise. This was majorly because repetitiveness builds mastery of 388 skills which in turn provides control to the worker.

389 Work station design is also involved in the degree of worker control over their jobs. 390 Respondents stated that design of chairs, systems and cubicles enhances the control that they 391 have on their work. They said that appropriate workstation design for an 8-hour shift worker 392 can enhance control over their work. 
The respondents affirmed that if workers had meaning in their work leading to mental satisfaction, it magnifies worker's control over their job. This was indirectly related to the product knowledge of the employees. If the employees had more knowledge about the product/service they were working on, they experienced more control over their work.

Again, a major factor which has been contributing in all the three aspects of the job design is the rapport with the supervisor and peers. Respondents were of the view that good professional relationship with colleagues at work provides peace of mind, and because of this they felt they had more control over their work. But if the professional relationships were not good, then they felt lesser control over their work.

402 Work environment is another element that contributes majorly to the worker's control over the job. A few respondents related to the fact that more than work environment, it is the turbulence in the external environment such as political scenarios, that affects their control at work. The respondents specifically pointed at the political sit-ins and the floods in the region.

406 Characteristics of work also contributed to the worker's control ability. The respondents were 407 of the view that the characteristics of work were very well defined, and this was contributing to the ability of control that they had on their work.

\section{Discussion}

410 It has been indicated in the interviews that it is hard to disengage from call centre work. 411 Repetitive tasks and high level of surveillance makes call centre work more complex [32,33]. 412 Although repetitiveness also leads to mastery of skills, it does lead to musculo-skeletal 413 disorders which makes the task more difficult to achieve [8, 34].

414 It was felt that repetition also leads to monotony and boredom. Creativity and engagement are 415 essentially required during work. If employees could find meaning in their work, it can not 416 only make them happy but also more productive [35]. Unfortunately, employees in this study 417 reported lack of creativity and meaning in the work. The general rule of thumb for motivating 418 employees is extrinsic remuneration. This is also the first need for an employee when taking 419 Maslow's hierarchy of needs into account [36]. This means that the employees have a tangible 420 reward to take home. A lack of this form of motivation can indirectly reduce intrinsic 421 motivation of an employee as well [37]. The remuneration for the employees, according to their 422 perception, was not in accordance to their expectations which led to de-motivation of the 423 employees.

424 It was also felt by the employees that a good network of supporting people is required in the 425 workplace to enhance the motivation of employees. This support should be available all the 426 time without any conditions [38]. It is important to mention here that according to the 427 participants, favours from a supervisor or colleague is as distressing as non-supportive 428 colleagues or an authoritative supervisor, because then these favours need to be returned. This 429 is why the respondents suggested that both good and bad working relations with people in the 430 workplace sometimes is a menace. 
Employees were happy with their job descriptions. They knew exactly how to do their job and

432 they were provided with adequate trainings related to their jobs. However, they were not happy 433 with non-provision of trainings for other areas. They were concerned that if they wanted to 434 change their job role, there was no support for it. It is important for an organization to let their employees experience other job roles as well to enhance their learning abilities [39].

436 Workers felt that if their work environment, including the ambience and workstation design be improved, it can enhance their motivation. The office design in fact in its totality is important

438 here; this includes lighting, acoustic and visual privacy, social interaction, layout and symbolic identification [40]. Beyond these factors, employees also mentioned extended factors such as political and social factors which influenced their work.

441 From the above discussion, it is apparent that the organization of work must be reorganized effectively to motivate employees for better performance and well-being [41].

\section{Recommendations}

444 In light of the above findings, the following recommendations are proposed.

1. Frequent breaks should be given at intervals during the 8 hour shift. This will break the monotony of the employees. Also this will help in lesser posture problems and the workers will not feel exhausted or burnt out.

2. Employee's compensation is lesser than expectations. This has happened mainly because of outsourcing the call centres. Because of this reason, the employees felt that their salaries are not at par with the effort in the job. This has created unrest among the employees of the call centres.

3. Employees are extremely bored because of the monotony and boredom at work. One of the reasons highlighted by respondents were non job related trainings or creativity at work. Because job descriptions are well outlined, employees follow them, but they hardly have anything to do beside those duties. They wanted to have more room and space to do something out of their job descriptions. It is recommended that they have one or two weeks of job rotation in one month, and then back to their main job.

4. Workstation design or system design should be constructed in such a way that it provides maximum accessibility and articulation of body parts of the employees. There is room for improvement regarding this aspect. Respondents stated the fact that they can feel they are more in control of their job if the workstation design is better.

5. Related and non-related job trainings and workshops should be imparted on a regular basis. This is because the employees felt more in control of their job when they have more product/service knowledge.

6. There should be flexibility in the supervision of the call centres employees. Some of the employees stated that they were treated like machines. Although there have been outdoor activities and other job rotation options too but the employees still related to the fact that Taylorism prevailed in this type of job.

7. There should be some contingency planning regarding turbulence in the political or natural environment. A disaster management committee should be formed to deal with 
484

485

486

487

488

489

490

491

\section{REFERENCES}

493 1. Ergoweb.com [Internet]. USA: Ergoweb LLC; c 1995 - 2019 [cited 2017 March 28]. 494 Available from: https://ergoweb.com/history-of-ergonomics/

495 2. Definition and Domain of Ergonomics [Internet]. Zurich: International Ergonomic 496 Association; [cited 2018 Feb16]. Available from: https:/www.iea.cc/whats/index.html

497 3. Marmaras N, Poulakakis G, Papakostopoulos V. Ergonomic design in ancient Greece. 498 Appl Ergon. 1999; 30(4): 361-368.

499 4. Hummon N P, Doreian P. Some dynamics of social balance processes: bringing Heider 500 back into balance theory. Soc Netw. 2003; 25(1): 17-49 
501 5. Suls J E, Wills T A E. Social comparison: Contemporary theory and research. Hillsdale, 502 NJ US: Lawrence Erlbaum Associates, Inc. ;1991

503 6. Rogers E M. Diffusion of innovations. New York: Free Press Simon and Schuster; 2010

504 7. Latour B. Reassembling the social-an introduction to actor-network-theory. New York:

505 Oxford University Press; 2005.

506 8. Waters T R, MacDonald, L A. Ergonomic job design to accommodate and prevent 507 musculoskeletal disabilities. Assist Technol. 2001;13(2): 88-93.

508 9. Harris C, Straker L. Survey of physical ergonomics issues associated with school 509 childrens' use of laptop computers. Int J Ind Ergon. 2000; 26(3): 337-346.

510 10. Resnick M L, Chaffin D B. An ergonomic evaluation of handle height and load in 511 maximal and submaximal cart pushing. Appl Ergon. 1995; 26(3): 173-178.

512 11. Sharan D. Ergonomic workplace analysis (EWA). Work. 2012; 41: 5366-5368.

513 12. Asensio Cuesta S, Diego Mas J A, Canós Darós L, et al. A genetic algorithm for the 514 design of job rotation schedules considering ergonomic and competence criteria. Int J Adv 515 Manuf Technol. 2012; 60(9-12): 1161-1174.

516 13. Meister D. An Outsider's View of Cognitive Ergonomics. In Proceedings of the Human 517 Factors and Ergonomics Society Annual Meeting. 2000; 44(6): 561-563.

518 14. Hollnagel E. Cognitive ergonomics: it's all in the mind. Ergonomics. 1997; 40(10): 11705191182.

520 15. Green T R G, Hoc J M. What is cognitive ergonomics? Trav Hum. 1991; 291-304.

521 16. McPhee B. Job and Workplace Design-Applying Occupational Ergonomics in Heavy 522 Industry. In Proceedings of the Human Factors and Ergonomics Society Annual Meeting $5232000 ; 44$ (28): 676-679.

524 17. Cohen J. The Role of Forensic Organizational Ergonomics. Ergonomics in Design: The 525 Quarterly of Human Factors Applications. 2011; 19(1): 29-32. 
526 18. Carayon P, Hoonakker P, Haims, M C. Participatory Ergonomics and Macroergonomic

527 Organizational Questionnaire Surveys. In Proceedings of the Human Factors and Ergonomics

528 Society Annual Meeting. 2002; 46 (15): 1351-1354

529 19. Thatcher A. Green ergonomics: definition and scope. Ergonomics. 2013; 56(3):389-398.

530 20. Das B, Sengupta A K. Industrial workstation design: a systematic ergonomics approach.

531 Appl Ergon. 1996; 27(3): 157-163.

532 21. Oldham G R, Hackman J R. Not what it was and not what it will be: The future of job

533 design research. J Organ Behav. 2010; 31(2-3): 463-479.

534 22. Johns G. Some unintended consequences of job design. J Organ Behav. 2010; 31(2-3):

$535 \quad 361-369$.

536 23. Hertel G. Motivating job design as a factor in open source governance. J Manage Gov.

537 2007; 11(2): 129-137.

538 24. Sprigg C A, Jackson P R. Call centers as lean service environments: job-related strain and 539 the mediating role of work design. J Occup Health Psychol. 2006; 11(2): 197.

540 25. Murray J, Jordan P, Bowden B. An Empirical Study of Job Design in the Australian Call

541 Centre Industry. Int J Employ Stud. 2004; 12(2).

542 26. Bagnara S, Marti P. Human work in call centres: A challenge for cognitive ergonomics.

543 Theor Issues Ergon Sci. 2001; 2(3): 223-237.

544 27. Kraemer T, Gouthier M. H. How organizational pride and emotional exhaustion explain

545 turnover intentions in call centers: a multi-group analysis with gender and organizational

546 tenure. J Serv Manage. 2014; 25(1): 125-148.

547 28. Moss P, Salzman H, Tilly C. Under construction: The continuing evolution of job

548 structures in call centers. Industrial Relations: A J of Econ Soc.2008; 47(2): 173-208.

549 29. Schulze, L.H. Workstation ergonomics. Prof Safety. 2000; 45(12):12.

550 30. Carayon P, Smith M J. Work organization and ergonomics. Appl Ergon. 2000; 31(6):

$551 \quad 649-662$. 
552 31. cdc.gov. [Internet]. Cincinnati: NIOSHC; [cited 2018 Feb 20]. Available from:

553 https://www.cdc.gov/niosh/docs/2002-116/pdfs/2002-

554 116.pdf?id=10.26616/NIOSHPUB2002116

555 32. Bain P, Watson A, Mulvey G, et al. Taylorism, targets and the pursuit of quantity and

556 quality by call centre management. New Technol., W and Employ. 2002; 17 (3):170-185.

557 33. Callaghan G,Thompson P. Edwards revisited: Technical control and call centres, Econ.

558 and Industrial Democracy. 2001; 22 (1):13-37.

559 34. Sprigg C, Stride C, Wall T, et al. Work characteristics, musculoskeletal disorders, and the 560 mediating role of psychological strain: A study of call center employees. J of Appl. Psychology. $561 \quad 2007 ;$ 92(5):1456-1466.

562 35. Knights D, McCabe D. Governing through Teamwork: Reconstituting Subjectivity in a 563 Call Centre. J of Manag. Stud. 2003; 40(7):1587-1619.

564 36. Hall D, Nougaim K. An examination of Maslow's need hierarchy in an organizational 565 setting. Organizational Behav. and Hum Perform. 1968; 3(1): 12-35.

566 37. Malhotra N, Budhwar P, Prowse P. Linking rewards to commitment: an empirical 567 investigation of four UK call centres. The International J of Hum Resour. Manag. 2007; 18(12): $568 \quad 2095-2128$.

569 38. Deery S, Iverson R, Walsh J. Coping Strategies in Call Centres: Work Intensity and the 570 Role of Co-workers and Supervisors. br J of Industrial Relations. 2010; 48(1):181-200.

571 39. Eriksson T, Ortega J. The Adoption of Job Rotation: Testing the Theories. ILR Rev. 2006; 572 59(4): 653-666.

573 40. Wineman J. Office Design and Evaluation. Environ and Behav. 1982;14(3): 271-298.

574 41. Frenkel S, Tam M, Korczynski M, et al. Beyond bureaucracy? Work organization in call 575 centres. The International J of Hum Resour. Manag. 1998; 9(6): 957-979.

576

577

578

579 